http://jmscr.igmpublication.org/home/ ISSN (e)-2347-176x ISSN (p) 2455-0450 crossref DOI: https://dx.doi.org/10.18535/jmscr/v8i1.61

\author{
(D) Journal Of Medical Science And Clinical Research \\ IGM Publication \\ An official Publication of IGM Publication
}

\title{
Evaluation of Fetal Doppler Indices in Patients with Pregancy Induced Hypertension and Healthy Pregnant Patients with Impact on Fetal Growth
}

Authors

\author{
Navneet Kaur Risam ${ }^{1}$, Sheema Posh ${ }^{2 *}$, Sheetal Sharma ${ }^{1}$, Sajjad Ahmad Dar ${ }^{3}$ \\ ${ }^{1}$ PG Scholar, Department of Radiodiagnosis and Imaging Government Medical College, Srinagar \\ ${ }^{2}$ Senior Resident, Department of Obstetrics and Gynecology, Skims, Srinagar \\ ${ }^{3}$ Professor and Head, Department of Radiodiagnosis and Imaging Government Medical College, Srinagar \\ *Corresponding Author \\ Sheema Posh
}

\section{Introduction}

Doppler study of the uteroplacental circulation was first suggested as a method of pregnancy assessment by Campbell and colleagues, ${ }^{1}$ who observed that Doppler flow velocity waveforms (FVW) were abnormal in pregnancies complicated by pregnancy-induced hypertension (PIH) and intrauterine growth retardation. In recent years a number of Doppler ultrasound studies of the uteroplacental circulation have confirmed the original observation that increased impedance to flowin these vessels is associated with an increased risk for subsequent development of preeclampsia and/or FGR. ${ }^{2}$. IUGR is thought to be the consequence of impaired trophoblastic invasion of the maternal spiral arteries and the physiological reduction in vascular resistance in the uteroplacental circulation ${ }^{1,3-7}$.

It is essential to accurately predict intrauterine growth restriction to facilitate monitoring and preventive treatment so that better maternal and perinatal outcome is achieved ${ }^{8}$. Women with normal uterine artery Doppler results are unlikely to develop preeclampsia, FGR or placental abruption and therefore do not necessarily need antenatal follow-up that is as close as that required in women with abnormal uterine artery Doppler findings 9 .

\section{Aim}

Evaluation of fetal Doppler indices and fetal groeth in patients within and without pregnancy induced hypertension.

\section{Materials and Methods}

Ethical clearance was obtained from the institutional ethical committee. 20 untreated patients with $\mathrm{PIH}$ and 40 healthy women with singleton pregnancies (matched for maternal age and gestational age) after 28 weeks of gestation underwent fetal Doppler studies with fetal biometry in a single sitting. Patients were evaluated for uteroplacental and fetoplacental insufficiency as well as fetal growth restriction and correlation between them was assessed in PIH and healthy pregnant patients.

Ultrasound and doppler studies were performed by a 3.5 -5 MHz probe on GE Logic S8 after 3-5 minutes of rest. Bilateral fetal middle cerebral artery (MCA), umbilical artery (UA) and bilateral uterine arteries (UT A) were evaluated and their pulsatility indices (PI), resistivity indices (RI) and peak systolic velocities (PSV) were noted. 5 
consecutive waveforms representing the lowest vascular resistance were taken and PI was calculated using these waveforms. Fetal biometry \{ with documentation of fetal head circumference (HC), abdominal circumference (AC), biparietal diameter (BPD), fetal femur length (FL), fetal humeral length (HL) and estimated fetal weight $(\mathrm{EFW})\}$ was performed and comparison was made between these parameters in patients with and without PIH.

Blood pressure measurements were obtained by review of antenatal records.A systolic blood pressure of $\geq 140 \mathrm{mmHg}$ and diastolic blood pressure of $\geq 90 \mathrm{mmHg}$ after 20 weeks of gestation was taken as inclusion criteria. Complicated pregnancies and patients with preexisting hypertension were excluded from the study population.

Data was analyzed using IBM SPSS statistics version 23.0 software (SPSS Inc., Chicago, IL, USA). Measurement data was presented as mean \pm standard deviation (SD) and count data expressed as $\mathrm{n}(\%)$. The independent samples $\mathrm{t}$ test was used to compare the means of continuous variables. A two-tailed $\mathrm{p}$ values $<0.05$ was taken as statistically significant.

\section{Results}

The patients were matched for gestational age and maternal age, so no significant differences in demographic characteristics were observed between the study and control group. Umblical artery waveforms showed significant differences in RI, PI and S/D ratio.

Patients with PIH demonstrated significantly raised pulsatility index and resistance index of the uterine arteries as compared to healthy pregnant females. There was also presence of early diastolic notching in uterine arteries in these cases and these abnormal Doppler studies were more frequently associated with fetal growth restriction (Odds Ratio >1). Fetal growth restriction was noted in the study group as evidenced by significant differences in limb length as well as lower readings for estimated fetal weight.
Table 1: Patient characteristics in study and control group

\begin{tabular}{|l|c|c|c|}
\hline Characteristics & $\begin{array}{c}\text { Pregnant } \\
\text { women with } \\
\text { PIH(n=20) }\end{array}$ & $\begin{array}{c}\text { Pregnant } \\
\text { women without } \\
\text { PIH(n=40) }\end{array}$ & $\begin{array}{c}\boldsymbol{P} \\
\text { value }\end{array}$ \\
\hline Maternal age (Years) & $27.5 \pm 3.8$ & $28.8 \pm 3.4$ & 0.1 \\
\hline Gestational age (Weeks) & $32.85 \pm 3.6$ & $34.65 \pm 3.2$ & 0.06 \\
\hline Blood pressure(mmHg) & & & \\
\hline Systole & $148 \pm 12$ & $115 \pm 8$ & 0.001 \\
\hline Diastole & $96 \pm 7$ & $77 \pm 6$ & 0.001 \\
\hline
\end{tabular}

Table 2: Fetal Doppler indices in study and contol group

\begin{tabular}{|l|c|c|c|}
\hline Fetaldoppler indices & $\begin{array}{c}\text { Pregnant } \\
\text { women with } \\
\text { PIH( }(\boldsymbol{n}=\mathbf{2 0})\end{array}$ & $\begin{array}{c}\text { Pregnant } \\
\text { women without } \\
\text { PIH(n=40) }\end{array}$ & $\begin{array}{c}\boldsymbol{P} \\
\text { value }\end{array}$ \\
\hline Fetal MCA PI & 1.7 & 1.8 & 0.489 \\
\hline Fetal MCA RI & 0.8 & 0.9 & 0.418 \\
\hline Umbilical artery S/D ratio & 4.2 & 1.8 & 0.004 \\
\hline Umbilical artery RI & 0.74 & 0.45 & 0.001 \\
\hline Umbilical artery PI & 1.2 & 0.8 & 0.001 \\
\hline
\end{tabular}

Table 3: Uterine Artery Doppler Indices in study and control group

\begin{tabular}{|l|c|c|c|}
\hline $\begin{array}{l}\text { Doppler indices of b/l } \\
\text { uterine arteries }\end{array}$ & $\begin{array}{c}\text { Pregnant } \\
\text { women with } \\
\text { PIH(n=20) }\end{array}$ & $\begin{array}{c}\text { Pregnant } \\
\text { women without } \\
\text { PIH(n=40) }\end{array}$ & $\boldsymbol{P}$ value \\
\hline RT UT A PSV(cm/s) & 95 & 93 & 0.894 \\
\hline RT UT A RI & 0.62 & 0.46 & 0.002 \\
\hline RT UT A PI & 1.18 & 0.78 & 0.002 \\
\hline LT UT A PSV(cm/s) & 88.9 & 101.8 & 0.263 \\
\hline LT UT A RI & 0.62 & 0.50 & 0.002 \\
\hline LT UT A PI & 1.19 & 0.99 & 0.001 \\
\hline UT artery notching(n) & $7(\mathrm{~b} / \mathbf{l})$ & $2(\mathrm{~b} / \mathrm{l})$ & - \\
\hline
\end{tabular}

Table 4: Fetal Biometric parameters in study and control group

\begin{tabular}{|l|c|c|c|}
\hline $\begin{array}{l}\text { Fetal biometric } \\
\text { parameters }\end{array}$ & $\begin{array}{c}\text { Pregnant patients } \\
\text { with PIH (n=20) }\end{array}$ & $\begin{array}{c}\text { Pregnant females } \\
\text { without PIH(n=40) }\end{array}$ & $\begin{array}{c}\text { P } \\
\text { value }\end{array}$ \\
\hline $\mathrm{BPD}(\mathrm{cm})$ & 8.0 & 8.3 & 0.156 \\
\hline $\mathrm{AC}(\mathrm{cm})$ & 28.2 & 30.3 & 0.032 \\
\hline $\mathrm{FL}(\mathrm{cm})$ & 6.0 & 6.4 & 0.041 \\
\hline $\mathrm{HL}(\mathrm{cm})$ & 5.3 & 5.7 & 0.029 \\
\hline $\mathrm{EFW}(\mathrm{gm})$ & 1983 & 2314 & 0.122 \\
\hline $\mathrm{AFI}(\mathrm{cm})$ & 12.4 & 13.1 & 0.521 \\
\hline
\end{tabular}

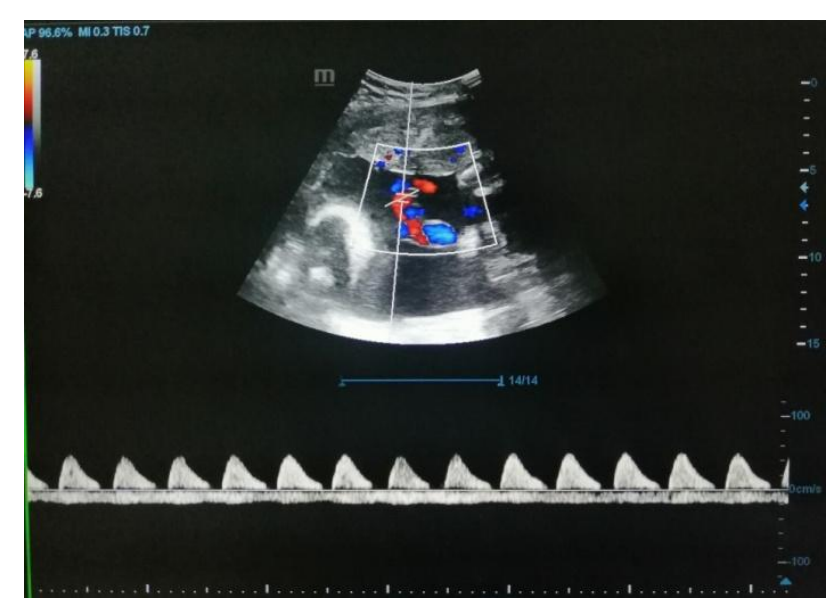

Fig 1: Absent diastolic flow in umbilical artery 


\section{JMSCR Vol||08||Issue||01||Page 397-400||January}

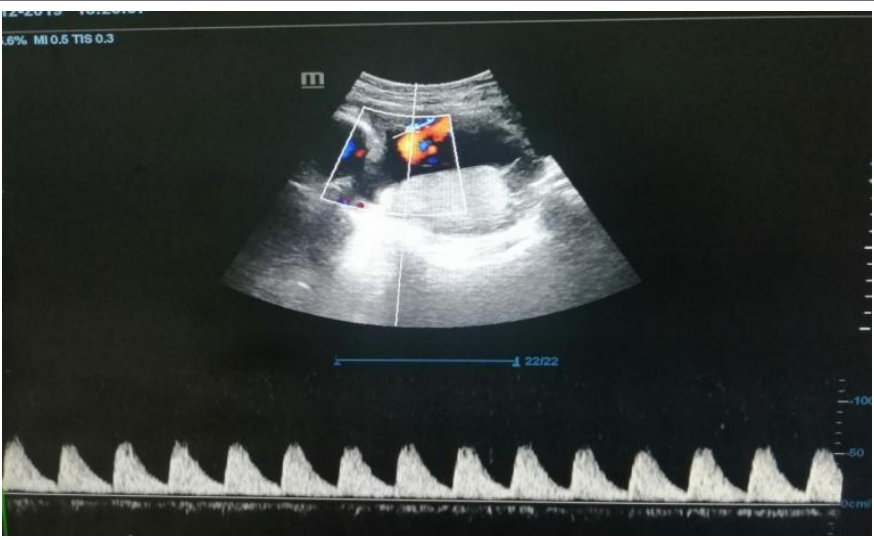

Fig 2: Reduced diastolic flow in umbilical artery

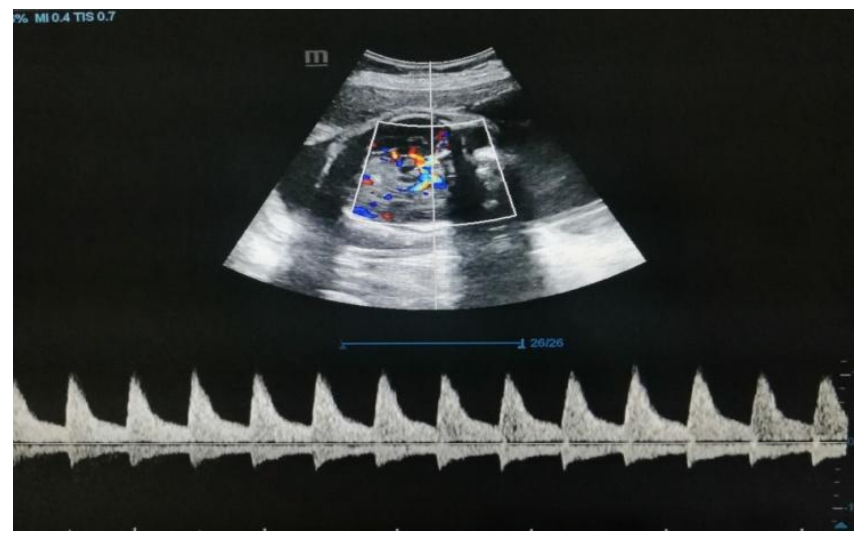

Fig 3: High resistance flow in fetal MCA

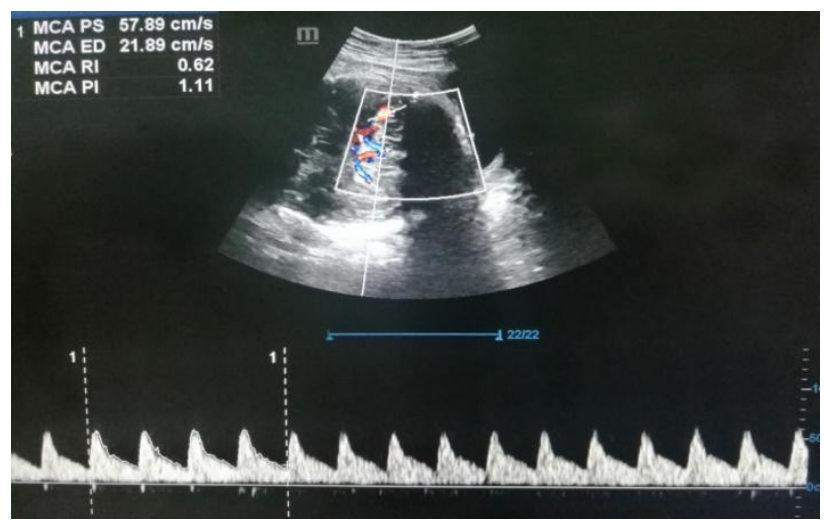

Fig 4: Increased diastolic flow in fetal MCA

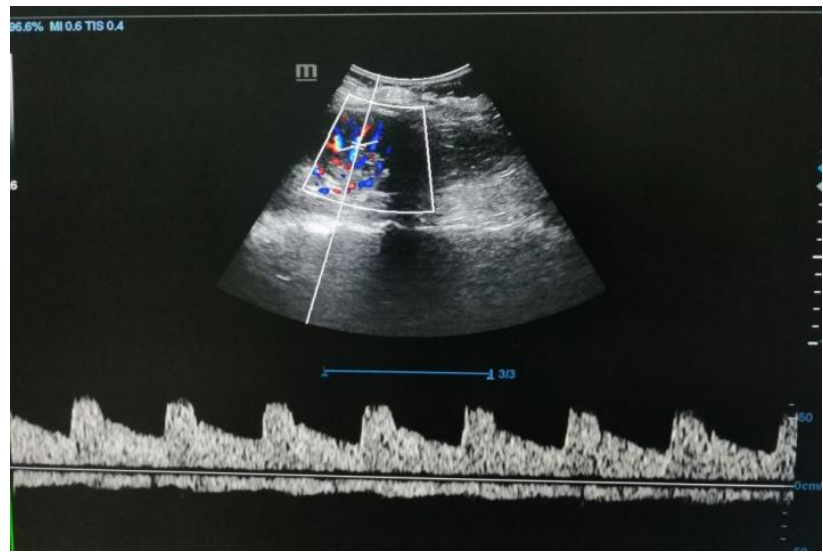

Fig 5: Low resistance uterine artery waveform

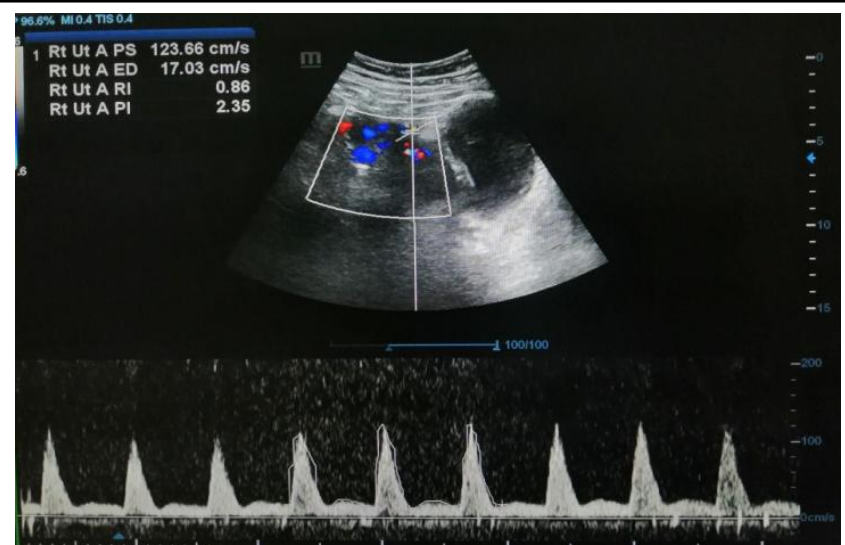

Fig 6: High resistance uterine artery waveform with early diastolic notching

\section{Discussion}

Pregnancy induced hypertension is one of the commonest complications in pregancy; seen in upto $7 \%$ of all pregancies.

Many studies have established a correlation between PIH and fetal growth restriction. Increased impedance to flow in uterine vessels is associated with subsequent IUGR ${ }^{2}$.

We propose that in addition to uterine artery notching, quantitative assessment of the uterine artery Doppler waveforms should also be used routinely as part of fetal Doppler assessment as the Doppler Indices of uterine artery RI and PI show a statistically significant difference in PIH/ Non-PIH pregnancies and are positively correlated with fetal IUGR. As such an objective assessment of Doppler waveforms may be more useful than noting uterine artery notching patterns.

Our findings are similar to those obtained by Papageorghiou AT et $\mathrm{al}^{10}$, who found uterine artery PI to be an early indicator of fetal IUGR and pre-ecclampia. However we have taken Doppler readings late in gestation to eliminate confounding factor of physiological changes in Doppler waveforms with gestational age.

\section{Conclusion}

There is a positive correlation between fetal growth restriction and abnormal fetal Doppler studies. In particular presence of bilateral uterine artery notching should prompt careful fetal growth assessment. 


\section{References}

1. Campbell S, Diaz-Recasens J, Griffin D, et al. New doppler technique for assessing uteroplacental blood flow. Lancet 1983; 1: 675-79

2. Campbell S, Pearce JM, Hackett G, Cohen-Overbeek T, Hernandez C. Qualitative assessment of uteroplacental blood flow: early screeningtest for highrisk pregnancies. ObstetGynecol1986; 68: 649-53

3. Brosens I, Robertson WB, Dixon HG. The physiological response of the vessels of the placental bed to normal pregnancy. $J$ PatholBacteriol1967; 93: 569-79

4. Pijnenborg R, Bland JM, Robertson WB, Brosens I. Uteroplacental arterial changes related to interstitial trophoblastic migration in early human pregnancy. Placenta 1983; 4: 397-14

5. McParland P, Pearce JM. Doppler blood flow in pregnancy. Placenta 1988; 9: 42750

6. Khong TY, De Wolf F, Robertson WB, Brosens I. Inadequate maternal vascular response to placentation in pregnancies complicated by pre-eclampsia and by small-for-gestational age infants. $\mathrm{Br} J$ ObstetGynaecol1986; 93: 1049-59

7. Aardema MW, Oosterhof H, Timmer A, Rooy I, Aarnoudse JG. Uterine artery Doppler flow and uteroplacental vascular pathology in normal pregnancies and pregnancies complicated by pre-eclampsia and small for gestational age fetuses. Placenta 2001; 22: 405-11

8. Coomarasamy A, Papaioannou S, Gee H, et al. Aspirin for the prevention of preeclampsia in women with abnormal uterine artery Doppler: a meta-analysis. Obstet Gynecol2001;98:861-6.
9. Albaiges $\mathrm{G}$, Missfelder-Lobos H, Lees C et al. One-stage screening for pregnancy complications by colour Doppler assessment of uterine ateries at 23 weeks of gestational age. Obstet Gynecol. Oct 2000; 96 (4): 559-64

10. Papageorghiou AT, Yu CKH, Bindra R et. Multicenter screening for pre-eclampsia and fetal growth restriction by transvaginal uterine artery Doppler at 23 weeks of gestation. Ultrasound Obstetgynecol 2001. 18: 441-449. 